\title{
Are central venous catheter repairs worthwhile? An analysis of long term catheter repairs
}

\author{
A. Kilsby, Y. Pasha, B. Shandro, S. Crowther, S. Kay, M. Small, J. M. Nightingale and S. M. Gabe \\ Lennard Jones Intestinal Failure Unit, St Mark's Hospital, Northwick Park, Watford Road, Harrow, \\ Middlesex, HAl $3 U J, U K$
}

There is little information on the effectiveness of central venous catheter (CVC) repairs in long term CVCs used for parenteral nutrition $(\mathrm{PN})$. There are two types of repair that can be used for this type of CVC: internal (involving catheter transection and hub and clamp replacement) and external (a superficial repair of the outer sheath only). Pollack et al. demonstrated that Broviac catheter repair avoided the removal of $7 \%$ of $\mathrm{CVCs}^{(1)}$. Hwang et al. studied tunnelled triple lumen CVCs and showed that a repair did not result in a significant increase in catheter longevity ${ }^{(2)}$. There are no studies reporting the success of repairs on long term CVCs used for PN.

Using our intestinal failure database we performed a retrospective analysis of CVC repairs on patients with long term CVCs for PN from Jan 2006 - June 2011. A total of 77 CVC repairs were performed. 8 internal repairs were immediately unsuccessful, necessitating catheter replacement. 69 repairs (42 external, 27 internal) were successful after 24 hours. Of these, 16 repairs (11 external, 5 internal) have had no further event to date. Some CVCs had multiple repairs. Each repair was categorised as internal or external and the number of days calculated to the next event on that line (further repair or replacement). Statistical analysis was performed using the Mann-Whitney and Kruskal-Wallis tests.

At the time of analysis, the avoidance of CVC change was $41 \%$ and $69 \%$ for internal and external repairs (lasting $>90$ days or currently in situ), respectively. The longevity of the repairs are shown below with data for the 16 CVCs still in situ with no further events excluded.

Table 1. Analysis of days to next event for internal vs. external repair

\begin{tabular}{|c|c|c|c|}
\hline & Internal repair median (range) & External repair median (range) & $P$ value \\
\hline Days to the next event & $36.5(2-549)$ & $104(2-659)$ & 0.29 \\
\hline
\end{tabular}

Table 2. Analysis of longevity of CVC repairs

\begin{tabular}{lcc}
\hline & $\begin{array}{c}\text { Internal repair } \\
\text { median (range) }\end{array}$ & $\begin{array}{c}\text { External repair } \\
\text { median (range) }\end{array}$ \\
\hline Longevity of 1st repair (days) & $40(2-549)$ & $133.5(2-659)$ \\
Longevity of 2nd repair (days) & $75(4-309)$ & $32.5(12-259)$ \\
Longevity of 3rd repair (days) & $36(15-37)$ & 57 \\
\hline
\end{tabular}

Table 3. Analysis of longevity of CVC repair by approach

\begin{tabular}{|c|c|c|c|}
\hline CVC approach & $\begin{array}{c}\text { Internal repair } \\
\text { median days (range) }\end{array}$ & $\begin{array}{c}\text { External repair } \\
\text { median days (range) }\end{array}$ & $P$ value \\
\hline Internal jugular vein $(n=36)$ & $32.5(2-222)$ & $139(5-364)$ & 0.15 \\
\hline Subclavian vein $(n=10)$ & $22(4-231)$ & $99(9-659)$ & 0.21 \\
\hline Femoral vein $(n=6)$ & $228.5(15-549)$ & $9(2-16)$ & - \\
\hline Renal $(\mathrm{n}=1)$ & - & 29 & - \\
\hline
\end{tabular}

The avoidance of CVC change is greater for external repairs than internal repairs. In both cases the percentage avoidance of CVC change appears to justify repairs as a worthwhile intervention. There is no significant difference for longevity of repair according to repair type, number of previous repairs or approach.

1. Pollack PF, Kadden M, Byrne WJ, Fonkalsrud EW \& Ament ME (1981) 100 patient years' experience with the Broviac silastic catheter for central venous nutrition. JPEN Journal Parenter Enternal Nutr 5(1):32-6.

2. Hwang F, Stavropoulos W, Shlansky-Goldberg R, Mondschein J, Patel A, Solomon J et al. (2008) Tunnelled Infusion Catheter Breakage: Frequency and Repair Kit Outcomes. J Vasc Interv Radiol 19(2):201-206. 